NASA-CR Latest developments in

166087

cryogenic safety.

N83-32676

LATEST DEVELOPMENTS IN CRYOGENIC SAFETY

Applied Cryogenics and Materials Consultants

New Castle, DE

$\operatorname{Mar} 83$

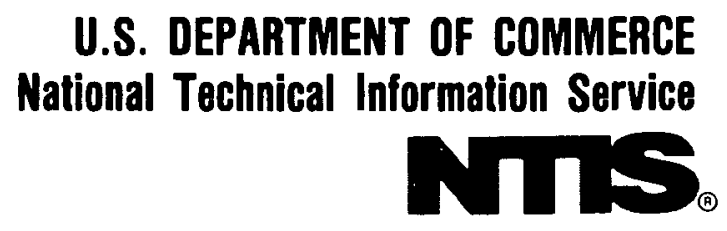


NASA Contractor Report 166087

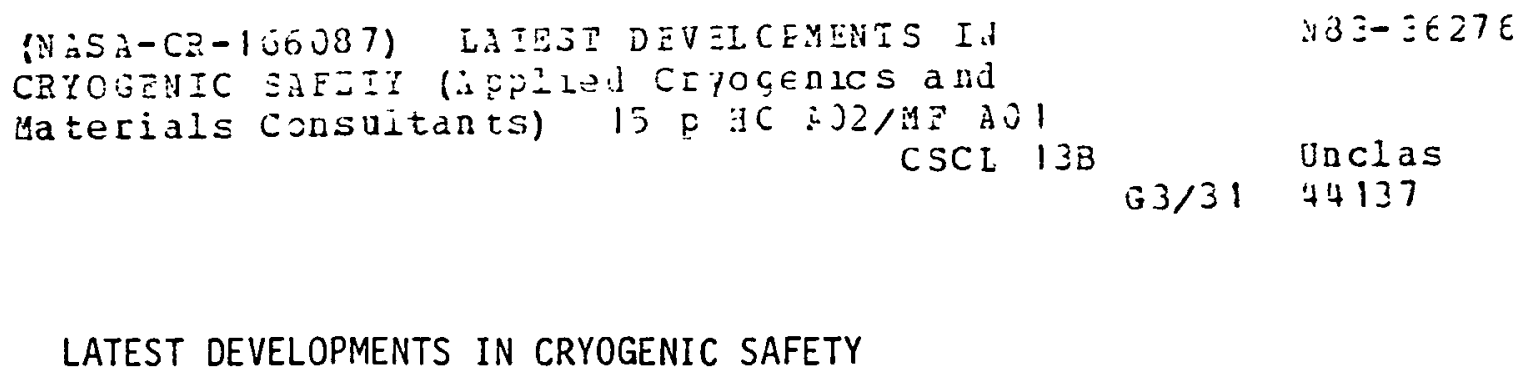

T. J. Webster

APPLIED CRYOGENICS AND MATERIALS CONSULTANTS

New Castle, Delaware 19720

Purchase Order L-44921B

March 1983

\section{N/Sn \\ National Aeronautics and \\ Space Administration




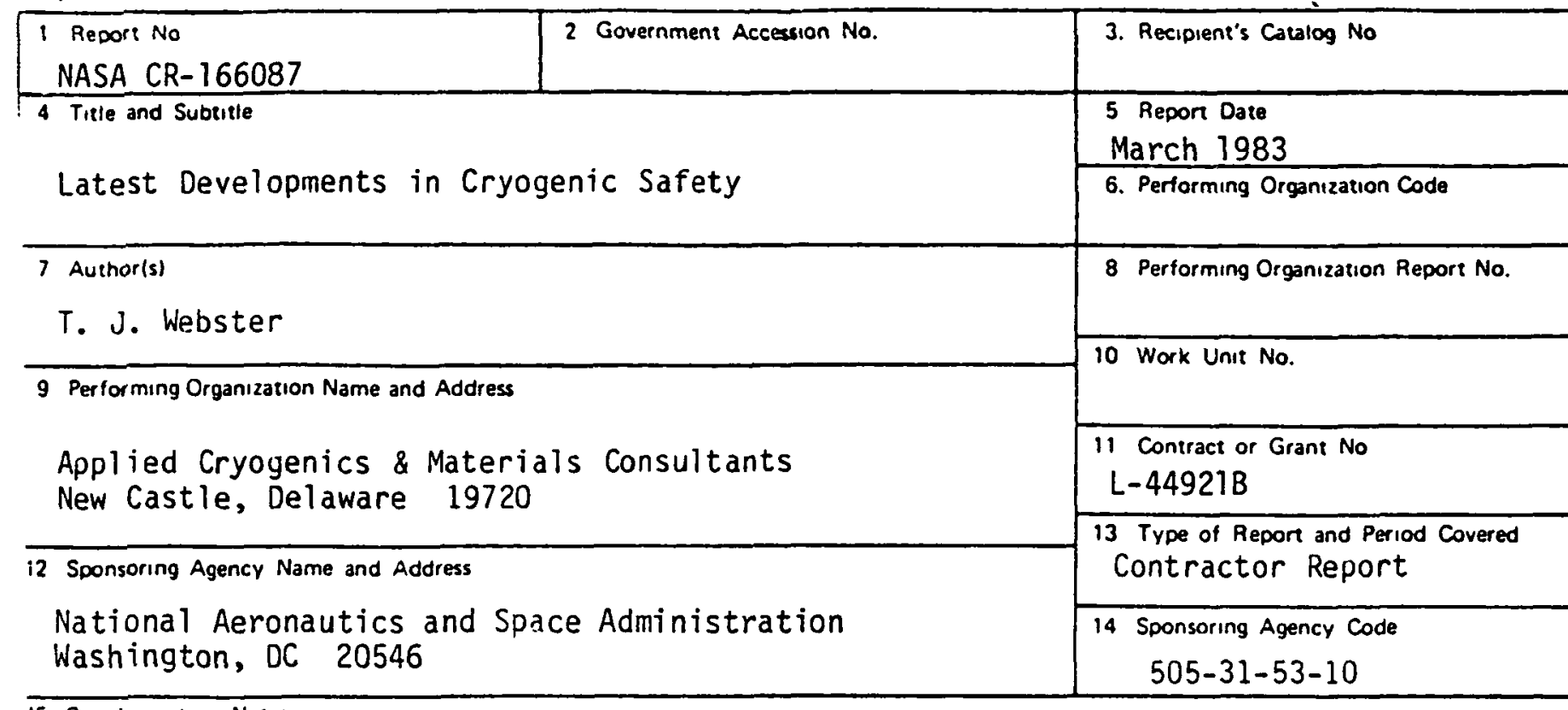

15 Supplementary Notes

Langley Technical Monitor: Dr. Robert A. Kilgore

This report is a special version of a paper presented at the Ninth International

Cryogenic Engineering Conference (ICEC9), Kobe, Japan, May 11-14, 1982.

16 Abstract

The Cryogenic Safety Manual, sponsored by the British Cryogenics Council, was published over 10 years ago. A new updated version is now available. Some general aspects of cryogenic safety are highlighted, and attention is drawn to some of the more unusual hazardous situations. An awareness of the physical properties of the cryogenic fluids being dealt with is important in directing attention to hazardous situations which may arise. Because of this, the more important properties of the cryogenic fluids are given, such as molecular weight, boiling point and freezing point. From these properties, hazardous situations can be deduced. There are hidden dangers that are not always easy to spot. Some of the unexpected hazards, most of which have led to deaths, are: asphyxiation (anoxia), frost bites and hypothermia, explosions, and combustion. The aim of this publication is to help bring about increased safety in the production and use of cryogenic products through a deeper appreciation of the scientific, technological and administrative steps which must be made if accidents, some fatal, are to be avoided in the future.

17. Key Words (Suggested by Author(s))

18 Distribution Statement

Liquid Nitrogen

Cryogenics

Safety

Cryogenic wind tunnels

Star Category - 31

Unclassified - Unlimited

\begin{tabular}{l|l|l|r|}
\hline $\begin{array}{l}\text { 9. Security Cassif lof this reportl } \\
\text { Unclassified }\end{array}$ & $\begin{array}{l}20 \text { Security Classif lof this pagel } \\
\text { Unclassified }\end{array}$ & $\begin{array}{l}\text { 21. No. of Pages } \\
14\end{array}$ & $\begin{array}{c}\text { Price } \\
A 02\end{array}$ \\
\hline
\end{tabular}




\title{
LATEST DEVELOPMENTS IN CRYOGENIC SAFETY
}

\author{
by Tom Webster DSc CEng FRSC FIChemE FInst Pet \\ Safety Consultant
}

\begin{abstract}
INTRODUCTION
The theme of this Conference points to the importance of Cryogenics in the future; for that future to be assured however it is vital that the interests of safety should receive the closest attention.

Accidents arising in the early use of a new method are especially important for, if they attract adverse criticism from Health \& Safety Authorities, this can jeopardise completely the future use of the method leading to the loss of what might otherwise have been a commercially attractive possibility. Safety in existing cryogenic processes is of course equally important.
\end{abstract}

Fortunately the Cryogenics Industry, largely because it was conceived and developed by scientists and engineers, has a good safety record but, due to the complexity of the technology it employs, the wide variety of fields it embraces and the ever increasing involvement of the public as product usage expands, accidents, many of which could have been avoided, are still occurring. The dissemination of safety information on Cryogenics in a readily digestible form is therefore vital at this point in time.

In the UK the British Cryogenics Council set up a panel of experts having considerable scientific and practical experience to examine cryogenic safety in a fully comprehensive way. The findings of this group have been published as a revision of the Cryogenics Safety Manual which was published by the BCC over 10 years ago and was felt to need updating. It is hoped that this book which covers:

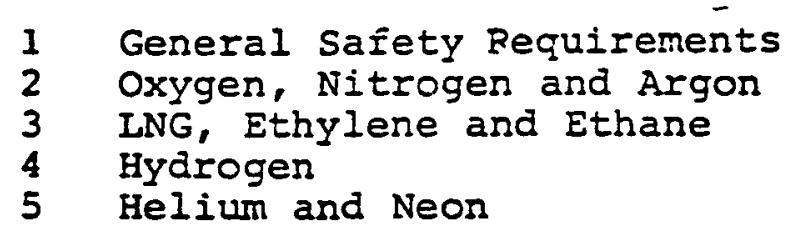

will lead to a fuller understanding of the problems that can arise in Cryogenics and to better all-round safety in this field.
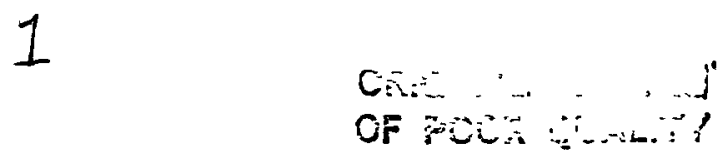


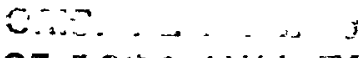

OF 3

In the present talk I wish to highlight some general aspects of Cryogenic safety and to draw attention to some of the more unusual hazard situations which may well be new even to people who have worked in cryogenics for quite some time.

\section{HAZARD AVOIDANCE - GENERAL}

Safety specialists often have a tendency to concentrate their efforts on particular aspects of safety, whilst neglecting the vitally important broader areas which are a prerequisite of good safety. Briefly, these can be said to cover:

(a) Hàrdware

- this must be properly designed and suitable for its purpose

(b) Mode of Operation - a well designed plant may fail if it is not operated properly

(c) Maintenance

- plants will not remain safe if they are not adequately maintained

(d) Organisation

- must be adequate to control (a) (b) and (c)

It is perhaps on (d) that there has been the greatest neglect, although Managements are becoming increasingly aware of the importance of this area. It is, for instance, pointless to devote time and effort to producing a rule book if there is no system for ensuring that the rules are being observed. Better by far to have fewer rules coupled with a mechanism to ensure that the rules are adhered to. A rule book filled with outdated and unnecessary rules will not earn the respect of workers and can therefore itself be regarded as a hazard. Managements tend to devote effort only to the creation of new rules, whereas it is equally important from the safety viewpoint to devote effort to the elimination of old outdated rules.

\section{RELATTIONSHIP BETWEEN SAFETY AND CRYOGENIC FLUID PROPERTIES}

An awareness of the physical properties of the cryogenic flulds being dealt with is important in directing attention to hasnrd situations which may ar1se. For this reason the llafaty Manunl atarta by listing the more important properties such as molecular weiaht, boiling point and ftampllit Hothllt. 'lahtlly a quick look at some of these, let us see some of the things we can deduce. 
(a) Molecular Weight

Hydrogen

Helium

oxygen

Nitrogen

Ethane

Argon

Krypton

Xenon

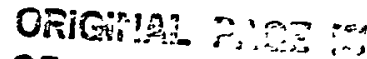

OF POC? D:?

Hydrogen and helium are very light and will clearly rise in air at normal temperature.

This knowledge, coupled with the fact that hydrogen readily forms explosive mixtures with air, means we must be on the alert for dangerous situations at high points in buildings in the event of a hydrogen leak. Also, it is no good trying to vent the gas at low level.

Argon is unexpectedly heavy and will be difficult to disperse from low lying badiy ventilated areas. Its removal from enclosed spaces will be better achieved by suction than by blowing.

\section{AIR}

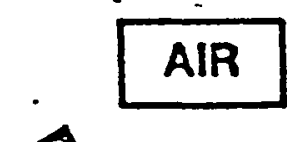

\section{SUCTION}
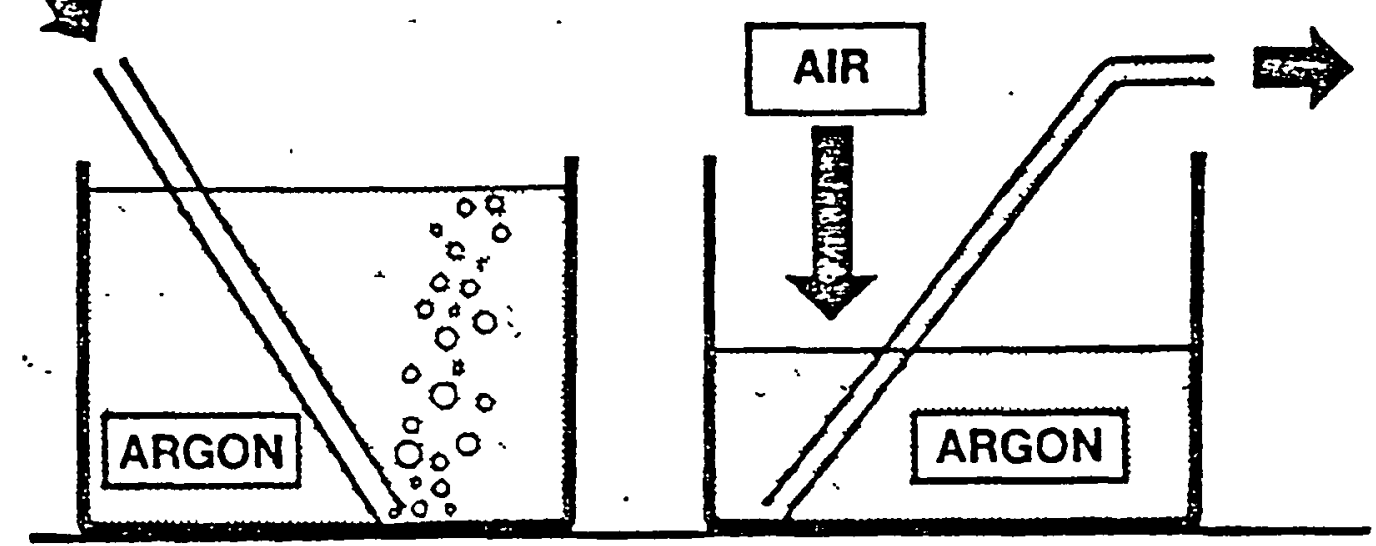

(b) Boiling Points and Freezing Points

$$
\text { Boiling Point Freezing Point }
$$

Oxygen
Nitrogen
Argon
Hydrogen
Helium

$-18$

$-196$

$-186$

$-253$

$-269$

$$
\text { ) Air }
$$$$
-219
$$$$
-210
$$$$
-189
$$$$
-259
$$ 
The boiling points in this slide show us the order of condensation of a number of different cryogenic fluids as temperature is reduced.

Air, which is a mixture of oxygen and nitrogen, will clearly condense if exposed to liquid nitrogen, thus the use of inert liquid nitrogen can lead to the creation of a non-inert atmosphere which supports combustion because it contains oxygen. This is why we prefer to use non-combustible insulant in vessels containing liquid nitrogen.

Designers sometimes forget that cryogenic gases can freeze. From the slide it can be seen that the boiling points of hydrogen and helium are so low that they will cause all other gases to freeze leading to possible plant blockages and in the case of hydrogen to the even greater hazard of solid oxygen formation.

The fact that the boiling point of argon is separated from the freezing point by only $3^{\circ} \mathrm{C}$ has led to the downfall of many a plant designer.

The Boiling Point slide also reminds us that very low temperatures are involved in cryogenic equipment and this dictates the metals of construction we can use. Embrittlement forces us to think in terms of stainless steel, aluminium and bronze. Incidentally, there is one area where low temperature assists the designer, namely, the increase in tensile strength which it produces. In the case of stainless steel, for instance, the tensile strength is doubled at low temperature providing a useful safety margin over room temperature predictions.

These very low temperatures are also going to involve problems of contraction of plant and the packing of insulant, if this is in the form of powder, making repeated warm-up for inspection undesirable and even hazardous.

Also, it should be remembered that a joint which is leak-tight at room temperature may well not be leaktight at low temperature.

(c) Volume Ratio Gas/Liquid

$\begin{array}{lr}\text { Oxygen } & 843 \\ \text { Nitrogen } & 683 \\ \text { Helium } & 740 \\ \text { Hydrogen } & 833 \\ \text { Neon } & 1415\end{array}$


The volume ratio gas/liquid on vaporisation of most cryogenic fluids lies between 600 and 800 . Neon is exceptional in having a ratio of 1415 .

(a) Iiquid Density

\section{Density at Normal Boiling point \\ ( $\mathrm{Kg} / \mathrm{Cu} \mathrm{M})$}

Hydrogen
Helium
Nitrogen
Oxygen
Xenon

71

125

808

1138

3040

The considerable density difference between hydrogen/ helium and oxygen/nitrogen should warn us not to use hydrogen/helium dewars for storing oxygen/nitrogen as the vessels may well be incapable of standing the extra weight. The situation is aggravated by the fact that hydrogen and helium vessels have to be designed to give maximum protection against heat inleak; conseguently their support systems tend to be relatively fragile.

From the few examples, it can be seen that the worker who takes the trouble to know something of the properties of the various cryogenic fluids he has to deal with will already have travelled a considerable distance along the road to safety. There are however many hidden dangers which are not always so easy to spot. These are dealt with in considerable detail in the revised Manual and I am certain that few people will read it without learning something new. I would like now to consider some of the urexpected hazards, most of which have led to deaths in the past.

\section{PHYSIOIOGICAI}

(a) Asphyxiation (Anoxia)

The increased use of inert gas during recent years has unfortunately not been matched by an increased awareness of the danger that can arise due to these gases being asphyxiants. This has led to many deaths. A lack of awareness of this hazard even by people who have enjoyed the highest levels of scientific training Is confirmed by the deaths which have occurred in the atomic energy and research fields, and in the chemical industry. 
Anoxia is of course lack of oxygen. Many people PR QUALiTy have an erroneous view of the time taken for lack of oxygen to have an effect on human beings. This is derived largely from films and the like about what happens in the case of submarine disasters with the victims gasping for breath for long periods.

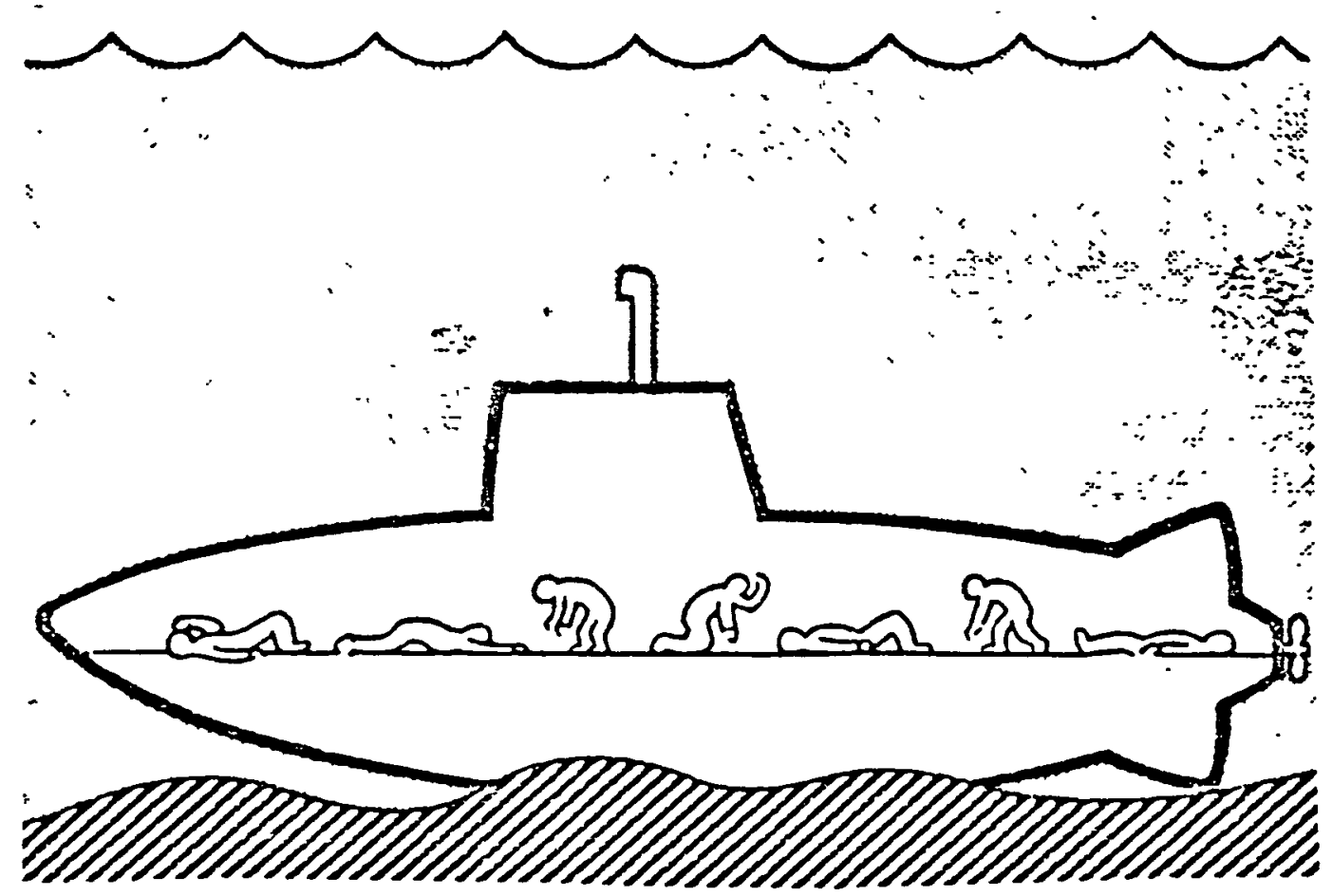

Rising carbon dioxide concentration in a submarine makes the victims breathe harder and this partly compensates for the lack of oxygen. In most industrial situations when oxygen shortage arises there is no increase in carbon dioxide concentration to warn the body to breathe harder and there is no gasping for breath. If oxygen is totally cut off, as could happen when breathing pure nitrogen or argon (or LNG or hydrogen for that matter), the victim goes down without warning as if struck on the head with a hammer and in a few minutes he will be dead.

The next slide which falls into the category of 'having a quick look' shows one manifestation of this type of accident where a man who knew nitrogen to be unbreathable decided to have a quick look in a tank which had been purged with nitrogen. He stuck his head in the tank, took one breath and was later found dead with the torch still alight in the bottom of the tank. Incidentally, it was wrongly assumed by the first investigators of this incident that the man had dropped the torch and bent down to get it. It is much more likely that he dropped the torch after first becoming unconscious. 


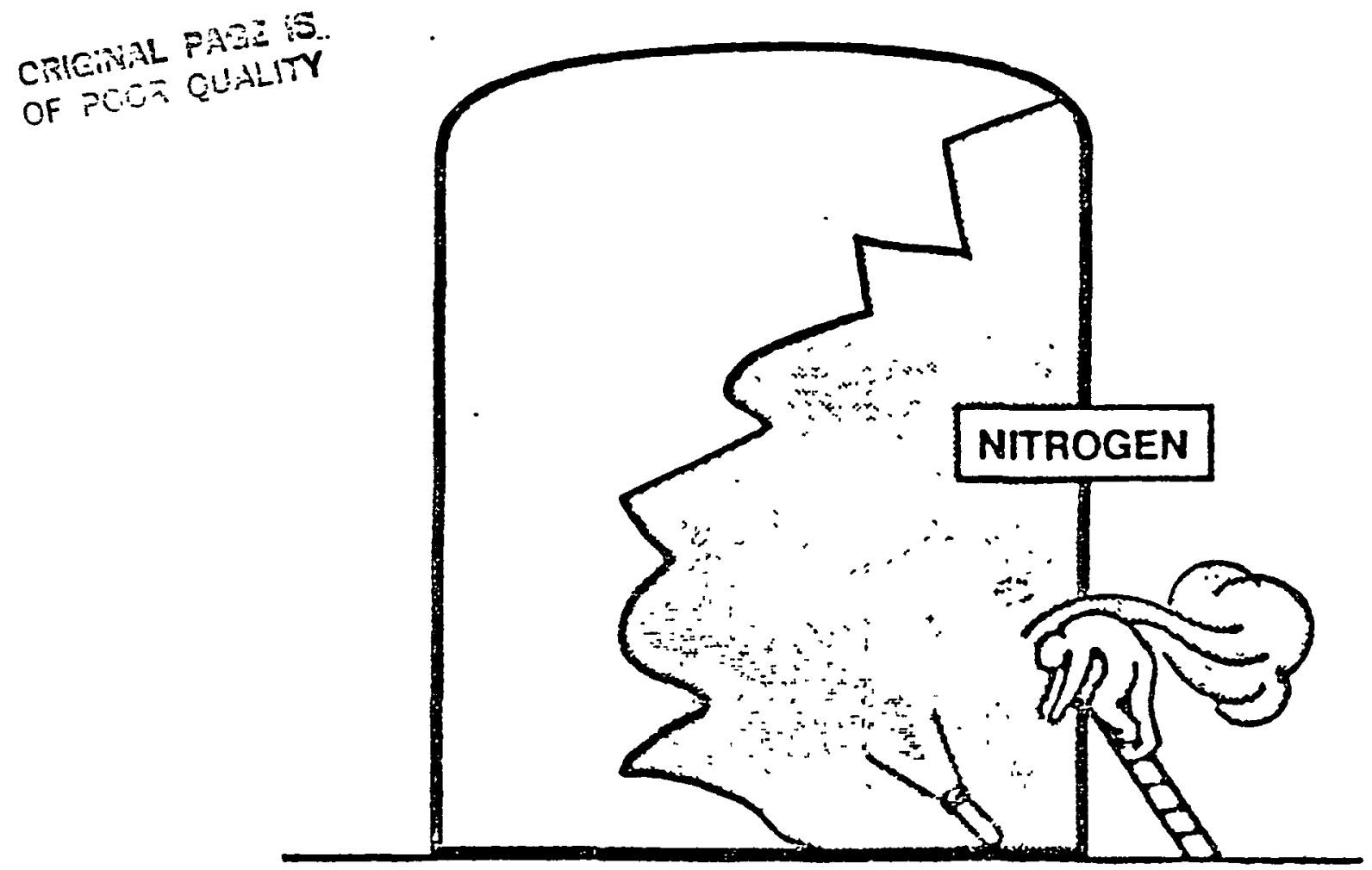

Another slide entitled 'Come up if you are short of breath depicts how a worker in the atomic energy field was told by a senior scientist to climb down into a vessel known to contain some argon. The man entered and was later found dear.

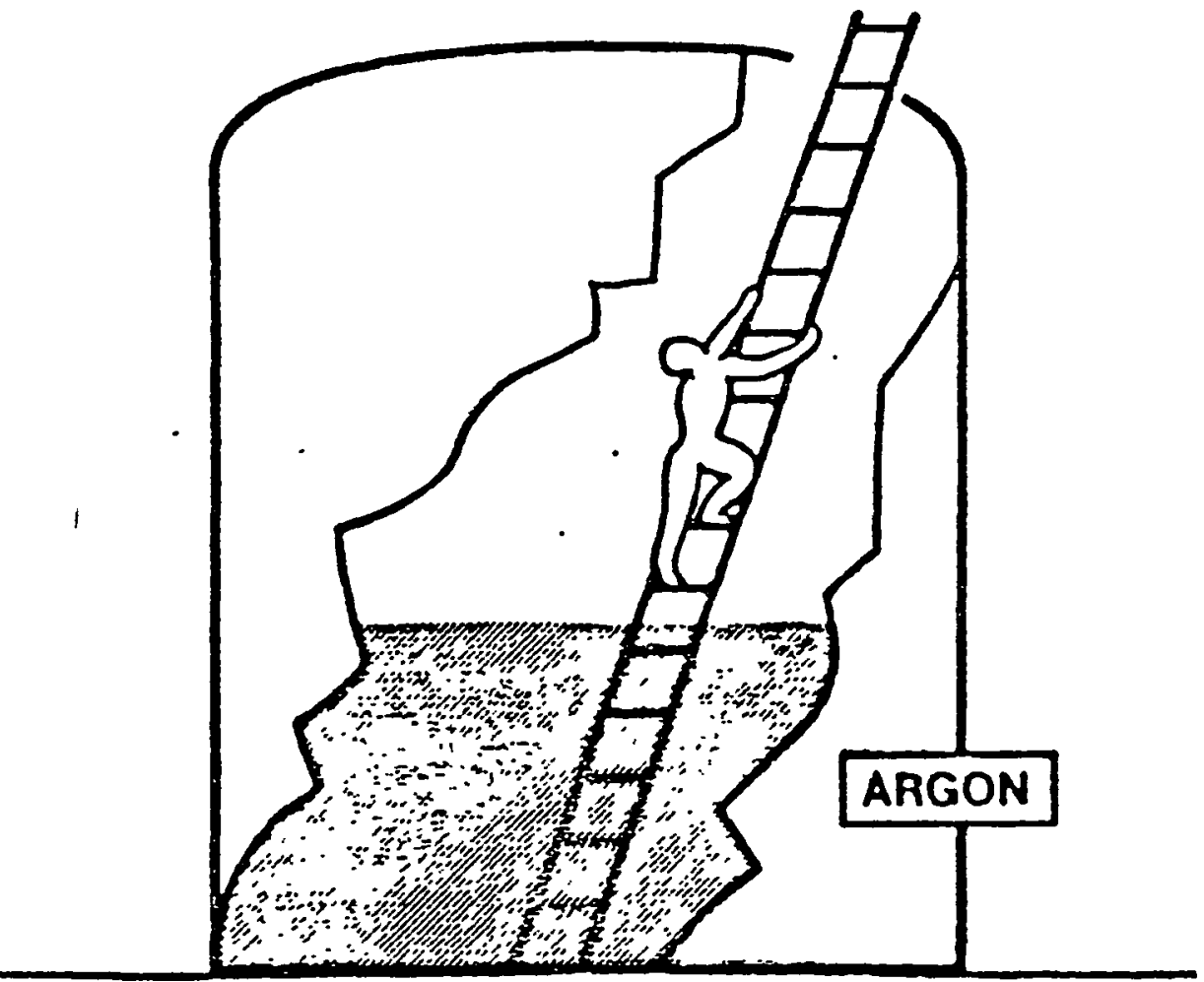


ORIGiAM PAOE IS OF PCOR QUAAT'

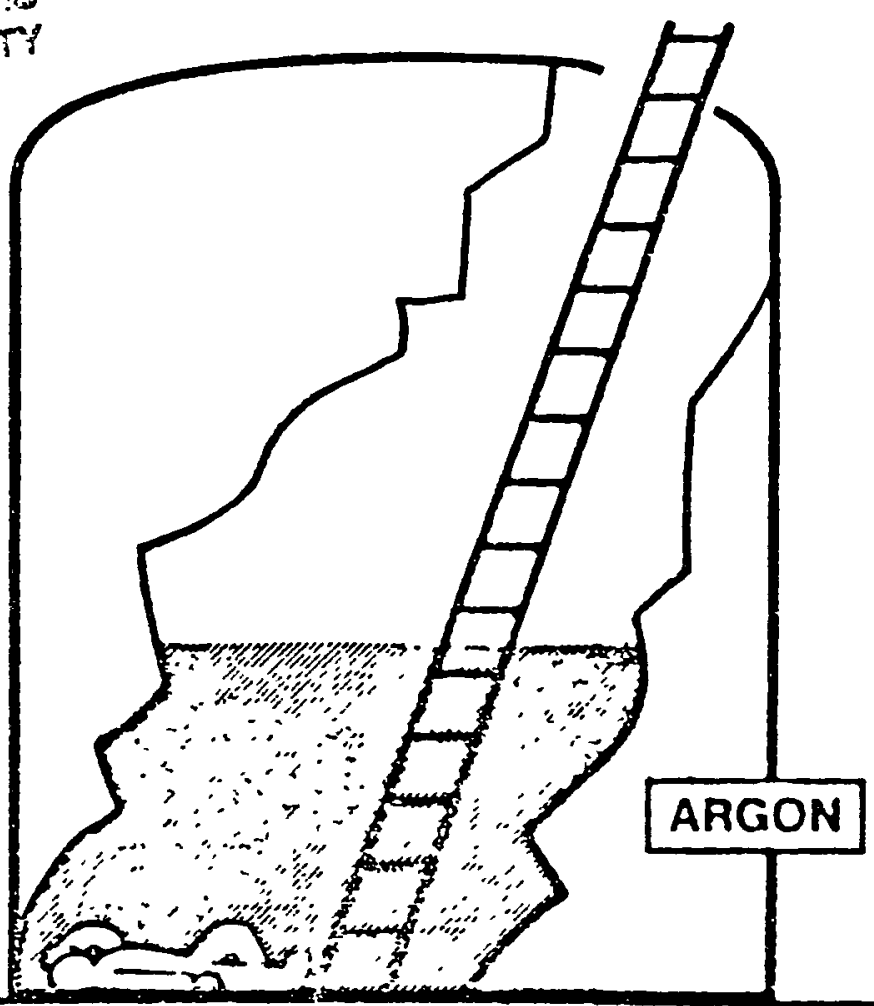

Another slide shows how the introduction of a hood to reduce noise can sometimes lead to a hazardous atmosphere due to the gradual leakage of inert gas from a compressor gland.

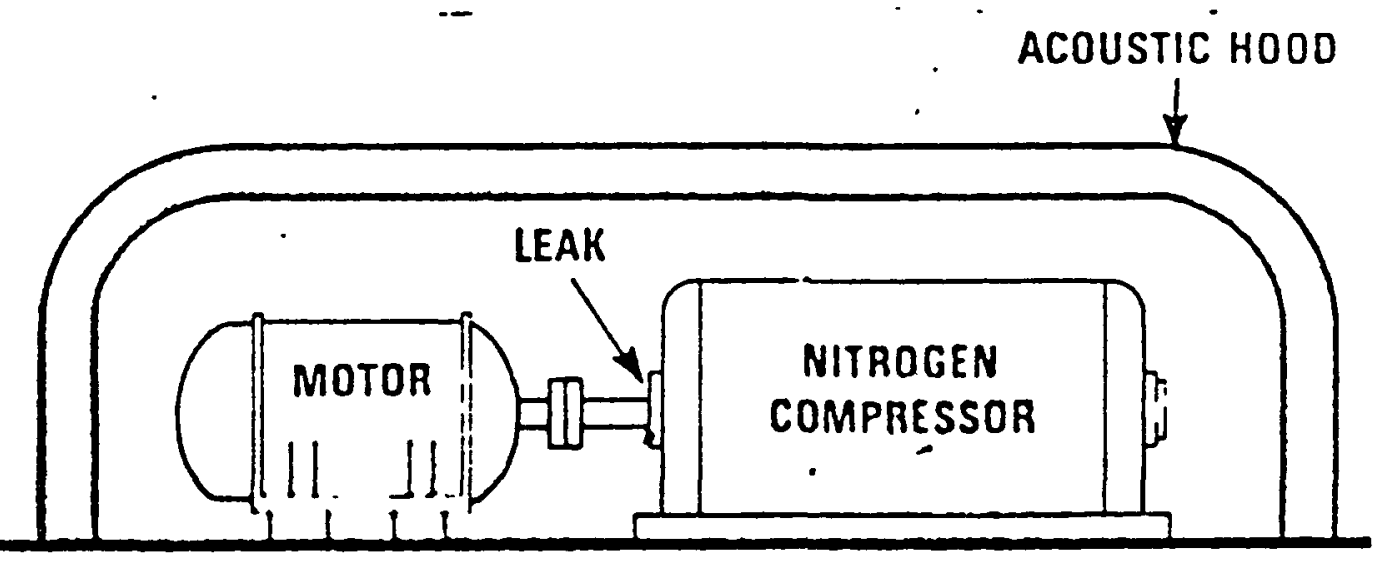

A particularly insidious aspect of asphyxiation accidents is that rescuers can all too easily themselves become victims. What is often forgotten 1s how difficult it is, even with ropes, to extract an unconscious man from an enclosed space such as a tank. A rescuer finding he cannot pull the man out will often rush in to lift the man out and himself become a victim. 
(b) Frostbite and Hypothermia

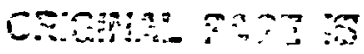

Cr PCOR QUALitiy

Many workers know little about frostbite and those who do have some knowledge have usually gained it as a result of the bitter experience of having been frostbitten through contact with cold products or metal.

Naked flesh will of course stick to uninsulated pipes cooled to very low temperatures. This is a truly terrifying experience. The worst example I have come across is when a small child gained access to a vacuum insulated oxygen evaporator (VIE) and stuck its tongue on the air heated vaporiser from which it was licking the snow.

The anaesthetising action of cold makes workers careless about getting treatment for frozen limbs and the actions to be taken in the event of frostbite are points on which people are remarkably illinformed.

Hypothermia is thought by many to be the concern of only the aged. Entry of even a relatively young person into deeply chilled vessels or tanks with inadequate clothing can lead to the person losing the strength of his limbs before he becomes aware of what is happening. The danger is greatest in sumertime when people are wearing light clothing.

Incidentally, if a man is sent to hospital with anoxia, frostbite or hypothermia, it is vital to advise the hospital what is the matter otherwise valuable time may be lost trying to diagnose the trouble and, likely as not, the diagnosis will be wrong and the victim will be treated for something he does not have.

\section{TECHNOLOGICAL}

(a) Nitrogen Explosion Hazards

At first sight readers may think this heading is incorrect, but this is not so.

As we saw earlier on, the condensation of air at Iiquid nitrogen temperature can lead to the formation of an oxygen-rich liquid and in contact with conbustibles this can result in the formation of what amounts to an explosive. 
Another way in which nitrogen can cause explosions is by the deoxidation of lubricants and surfaces in compressors handling nitrogen, leading to the formation of pyrophoric material. The sudden exposure of such machines to air can lead to violent explosions.

(b) Combustion

There is often a lot of confusion over materials which burn and those which support combustion. Hydrogen and hydrocarbons burn - oxygen supports combustion.

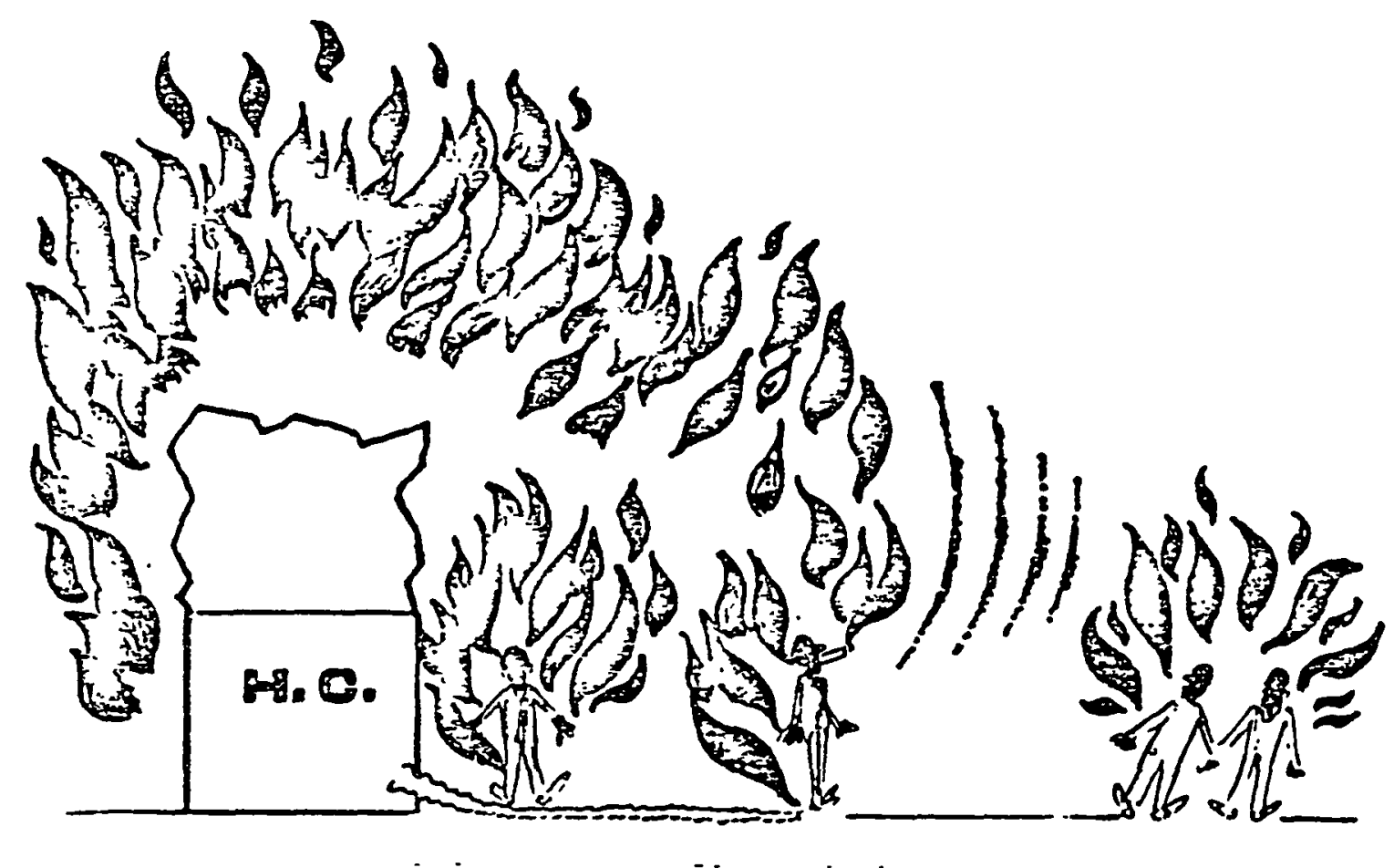

The slide shows what happens when an ING tank leak catches fire. The whole area is engulfed in flame and anyone unfortunate enough to be in the spill area will be burned. The fireball is likely to damage the tank and this can lead to the further escape of product. In other words we can rapidly find ourselves having to deal with a very serlous situation. 


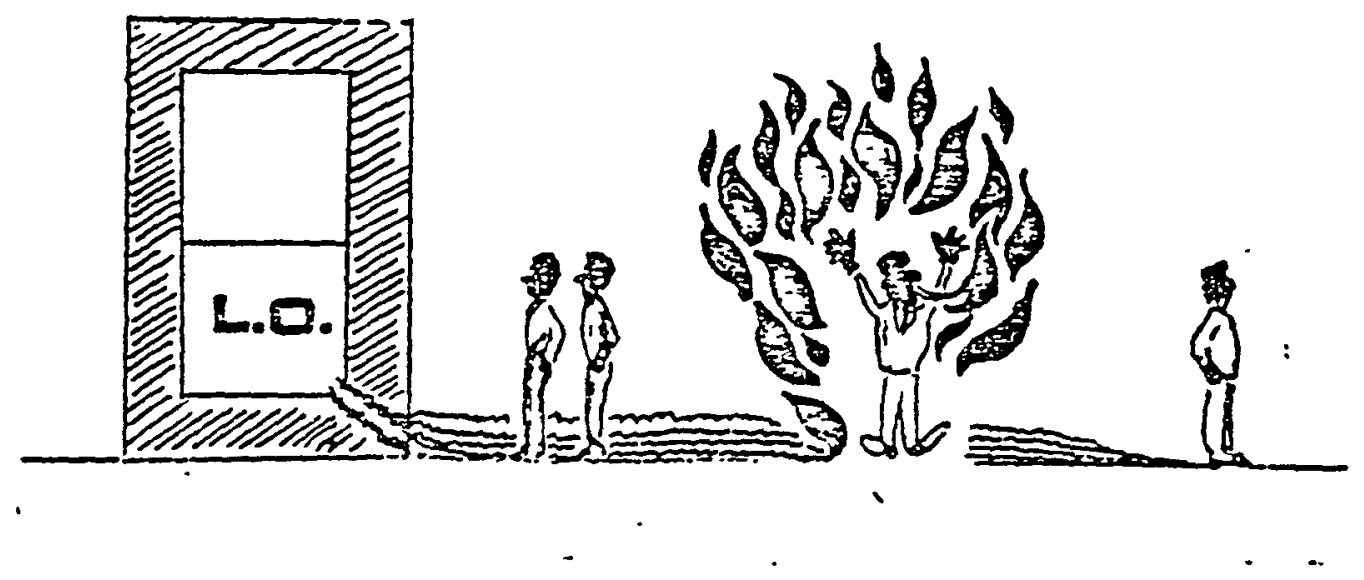

In contrast, consider an oxygen escape. Here one man who lights a cigarette goes up in flames, but there is no fire spread, other workers in the area are not affected and neither is the tank. We have a situation which, although very unpleasant for the individual lighting the cigarette, will be most unlikely to result in widespread damage.

When combustible gases and liquids escape into the atmosphere they will automatically find oxygen and all that is needed for disaster is a trigger. Much time is often wasted after incidents in argument as to what this trigger was - spark, friction, static electricity or naked flame. Such arguments, whilst interesting, are not likely to lead to measures which will prevent such incidents in the future, for in the case of hydrogen or hydrocarbon escape it is better to work on the premise that whenever a spill or an escape occurs a trigger capable of causing ignition is almost certain to arise. This greatly increases the emphasis on spill avoidance and leads to improved safety.

(c) Analytical

Certain combustible gas detectors rely on the presence of oxygen in the gas being sampled. If there is no oxygen present these instruments can give a false indication of safety.

It should also be remembered that instruments designed for operation at room temperature may not function properly at low temperature. 
(a) Total Vaporisation

It is often imagined that because a product such as liquid oxygen at a particular point in a plant contains a very low concentration of flammable impurity, no danger can arise. Workers forget that if product is totally vaporised certain impurities are liable to be deposited as solid which, if vaporisation continues, can build up to dangerous concentrations. A slide shows how this can arise in the case of the incorrect installation of an oxygen withdrawal line from a storage tank. A lute should be installed to prevent the vaporisation of liquid against the valve which is warm.

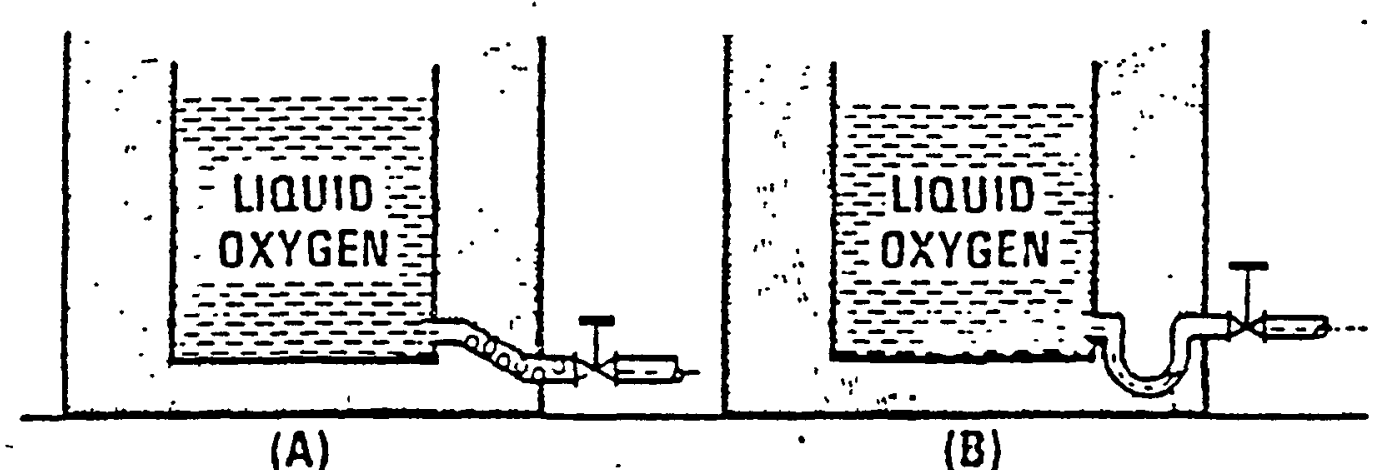

(e) Cold Migration

It is often forgotten that even with good insulation cold can find its way from cryogenic plants and tanks into the ground unless there is a positive heat barrier between the cold part and the ground.

For this reason tanks are usually put on stilts to make sure that the air gap between the tank and the ground will prevent the transmission of cold to the ground.

Insulation by itself is not enough, as can be seen from the example which shows a huge concrete plinth cracked by the cold emanating from a liquid nitrogen pipe embedded in it and insulated from it. As there was no heat break to the atmosphere a temperature gradient established itself in the concrete leading to the crack and in this case to a hazardous situation and great financial loss because the plinth was supporting an atomic accelerator designed to the highest of tolerances. 


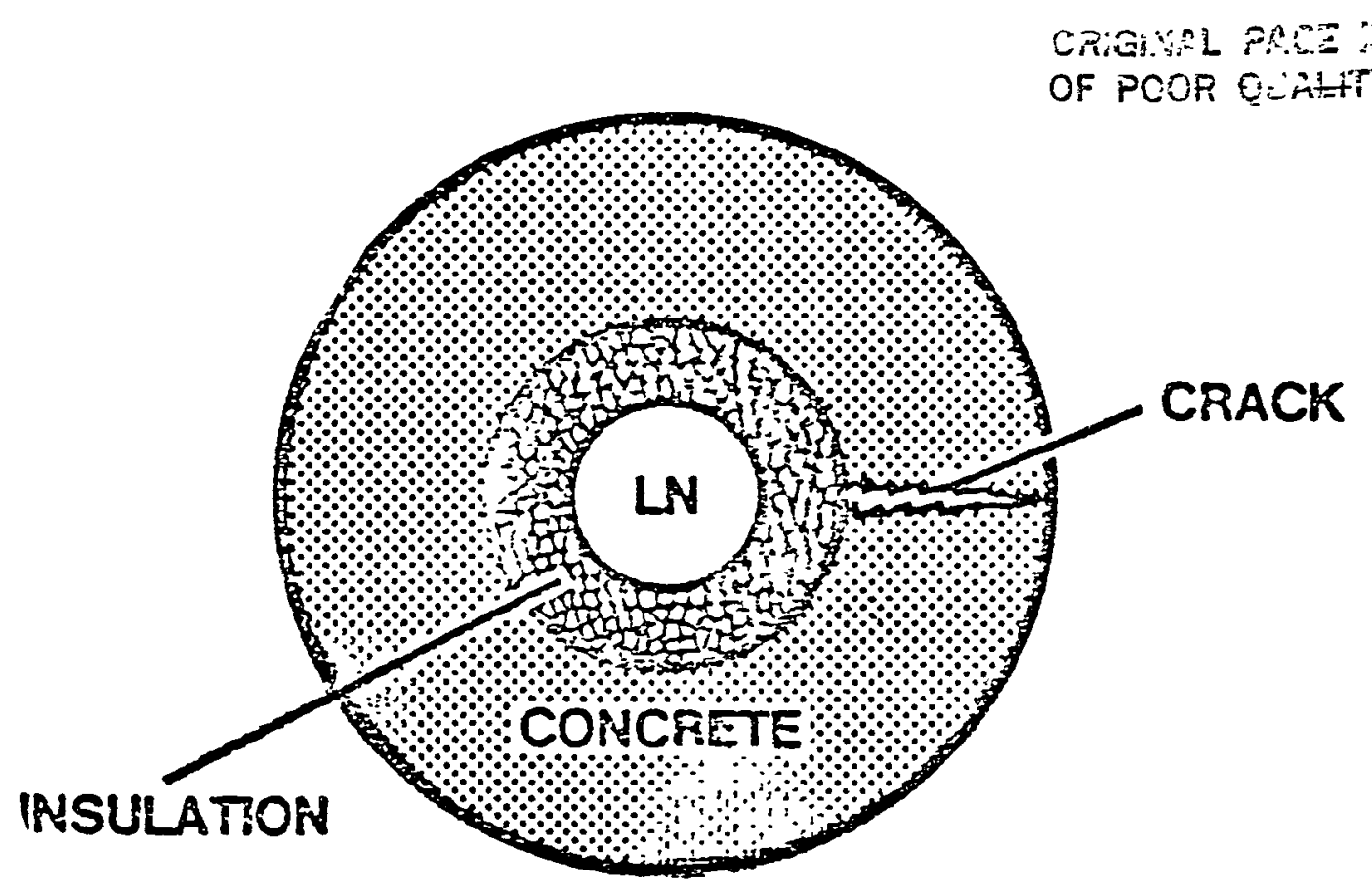

These are but a few of the topics dealt with in the British Cryogenics Council Cryogenics Safety Manual and in the book many other facets of Cryogenic Safety covering tie fluids listed in the introduction have been considered.

It is hoped that the publication will help to bring about increased safety in the production and use of Cryogenic products through a deeper appreciation of the scientific, technological and administrative steps which must be taken if accidents are to be avoided in future. 